\title{
El maestro de cantería Rodrigo Carrasco Gallego (c. 1640-1690) y su periodo toledano
}

\author{
ANTONIO José Díaz FERnándeZ
}

\section{RESUMEN: SUMMARY:}

En relación con el conocido arquitecto madrileño de la segunda mitad del s. XVII Rodrigo Carrasco Gallego († 1690), podemos ampliar la biografia del artista, documentando el periodo de su carrera que se podría denominar toledano, entre $1660 y$

1674 aproximadamente. Nacido hacia 1640 en Consuegra (Toledo), villa natal del arquitecto y pintor José Jiménez Donoso, Rodrigo Carrasco

se encuentra en esos años avecindado en Toledo, donde, formado dentro del círculo del maestro mayor Bartolomé Sombigo, ejerce su oficio de maestro de canteria, principalmente corno marmolista, en obras repartidas entre la ciudad del Tajo y otras localidades del entorno.
About of the celebrated architect madilenian belonging to the second half of the 17th century Rodrigo Carrasco Gallego (†1690), is possible amplify his biography, documentting the period of his career than colud call toledan, between 1660 and 1674 approximatly. Borned towards 1640 at Consuegra (Toledo), home town of the architect and páinter José Jiménez Donoso, Rodrigo Carrasco was living at those years at Toledo, where, formed inside the circle of the major master Bartolomé Sombigo, he exerts as master of stonework, mainly cutting of a marble, at works dispensed amog the city of the Tajo and localities of the environment.

Muchos son los datos referidos a la obra de Rodrigo Carrasco, maestro de cantería y tracista, activo en Madrid en el último cuarto del siglo XVII 1. Pero estas noticias sólo pertenecen al periodo madrileño de su carrera, sin duda el más conocido y de mayor plenitud, así como al último de

1 TOVAR MARTIN, V.: Arquitectos Madrileños de la segunda mitad del siglo XVII, Madrid, 1975. Los datos de la actividad madrileña de Rodrigo Carrasco, arquitecto, se resumen como sigue. En 12 de mayo de 1674 se obliga a la obra de cantería de la iglesia de Montserrat (pág. 110). En 21 de marzo de 1680 se obliga a hacer un sagrario y pedestal de mármoles para la sacristía de la capilla de la VOT, según su traza (pág. 149). En 1687 realizó el patio del colegio de Santo Tomás, según sus trazas (pág. 206). Colaboró con Marcos López en levantar un lienzo de la fachada de la cárcel de la Villa (pág. 321). En 20 de octubre de 1682 ajustaba la cantería de la enfermería de la VOT de $S$. Francisco, trazada por Marcos López y en 1683 diseña él la portada (pág. 331). Trazó el claustro de Santo Tomás, que contrató el maestro Juan de Bueras en 1678 (pág. 367). 
su vida puesto que fallece en la Villa y Corte en 1690. El Madrid cortesano de los grandes proyectos y construcciones barrocas supuso la meta profesional para este maestro especializado en cantería y marmolistería cuyos principios hay que rastrearlos en Toledo, ciudad de origen donde se formaría y donde ciertamente desarrolló sus mejores aptitudes y facultades como maestro en ejercicio ya desde la década de 1660 y hasta el tiempo de partida a la Corte, allá por 1672, aunque todavía frecuentara Toledo en razón de algunas obras que le ocupan en 1674 y a lo largo de 1675.

Habria que situar en torno a 1640 su nacimiento, que tiene lugar en la villa toledana de Consuegra sin que podamos indagar el año al no existir libros sacramentales de ese momento 2 . Lo cierto es que ya tempranamente residia en Madrid por el año de 1658, quizás en razón de su aprendizaje 3. Alcanzada su independencia profesional no tardará en establecerse en Toledo, donde en 30 de abril de 1662 es velado en la parroquia de San Miguel el Alto con Isabel Bautista, después de haber sido desposados el día 11 febrero de ese año en la de San Cebrián, de la que era parroquiana la contrayente 4. Avecindado luego en el barrio o parroquia de San Lorenzo, Rodrigo Carrasco aparece en abril de 1663 fiando a Francisco López, maestro del arte de la Seda, en el alquiler que éste hace de unas casas propiedad del Cabildo catedralicio en aquella colación parroquial, por tiempo de un año y en precio de 30 ducados 5 . En 4 de enero de 1665 bautiza en la mencionada iglesia a su primera hija, Maria, y en los años de 1667 y 1668 nacen Escolástica y Martín, respectivamente 6 .

2 Ni de la parroquia de Santa Maria ni de la de San Juan se conserva archivo anterior a 1700.

3 Archivo Histórico Provincial de Toledo (A.H.P.T.), Protocolo 153, folio 51, ante el escribano Eugenio de Valladolid. Escritura de poder otorgada en 19 de julio por Catalina Rodríguez, viuda del cantero Agustín Carrasco, y curadora de sus hijos, en favor de "Rodrigo Carrasco mi hermano ressidente en la $v^{a}$ de Madrid ...", para cobrar en su nombre una deuda del Conde de Montalbán por una obra ejecutada en el convento de franciscanos de la Puebla de Montalbán (Toledo).

4 Archivo Parroquial Stos. Justo y Pastor (A.P.J.P., Parroquia de San Miguel, Libro de Matrimonios 1653-1697, fol. 61. Fueron los padrinos Juan de Montealegre y Maria Carrillo, y los testigos, Marcos López y Diego de la Cruz. En la partida de S. Cebrián actúan de padrinos el padre y hermana de ella, Francisco Baptista y Maria Baptista, y asisten como testigos dos maestros canteros, Juan de Mendoza y Alonso Benito (Archivo Parroquial de S. Cipriano o S. Cebrián, Libro de Matrimonios 1649-1700, fol. 36v).

5 A.H.P.T., Pr. 3174 , fol 354 , ante Rodrigo de Hoz. La escritura es de 8 de abril y en ella se dice "Rodrigo carrasco marmolista".

6 A.P.J.P., Parroquia de San Lorenzo, Libro de Bautismos 1663-1691, fols. 19, 37v, 47v. En el bautizo de Maria Carrasco fueron los padrinos Alonso Moreno y María Torralba; los testigos, Pedro García Suelto, Tomé García y Pedro de Carvajal, todos vecinos de Toledo. Padrino de su hijo Martin fue Peáro González y testigo el pintor Hipólito de Torres (12-8-1668). 
La relevancia adquirida por el arquitecto Bartolomé Sombigo y Salcedo (1620-1682) en los especializados trabajos de decoración marmórea de la capilla de las Reliquias, el llamado Ochavo, de la catedral de Toledo, que ocupan una amplio periodo desde 1654 a 1671 , hicieron que aquél pronto dirigiera un selecto y cualificado equipo de artífices canteros de plena confianza, formado desde la década de los sesenta principalmente por los entonces oficiales Pedro González, designado primeramente como sobrestante del taller de piedra del Ochavo y luego como aparejador de las obras, Francisco de Huerta, que alcanzaria el título de sobrestante de las obras del Cabildo, y, desempeñando su actividad de "marmolista», Rodrigo Carrasco 7.

Aunque maestro que vive y ejerce en Toledo, a Rodrigo Carrasco le encontramos en 21 de agosto de 1666 en la ciudad jienense de Baeza a donde se habia desplazado para hacer postura en la obra de iglesia, claustro, celdas, sacristía, refectorio, cocina, escaleras, patios, jardín y fuente del colegio de San Felipe Neri, fundación del difunto señor don Fernando de Andrade y Castro, Arzobispo de Palermo y obispo de Jaén, conforme a la planta y alzados de Eufrasio López de Rojas, maestro mayor de obras de aquel obispado, en precio de 40.500 ducados, según expresas condiciones 8 . Al no adjudicarse la obra, ya en Toledo en octubre de 1666, Rodrigo Carrasco no reaparece documentalmente hasta finales de 1670 , en que actuó de fiador en la obligación del herrero Andrés Díaz de los Herreros para hacer una reja para la capilla de Santa Catalina en la parroquia de San Bartolomé de Toledo ${ }^{9}$. Pero sin duda esos años son los de su compromiso, junto a los también competentes maestros de Toledo

7 DIAZ FERNANDEZ, Antonio J.: El maestro mayor Pedro González (1640-1706), arquitecto toledano, 1998 (En prensa I.P.I.E.T.). A estos condiscipulos y compañeros encontramos precisamente en el bautismo de la hija de Pedro, Juana González, en 1668, siendo el padrino precisamente Rodrigo Carrasco y testigos Huerta y Luis de Maldonado (A.P.J.P., "LIBRO de Bautismos de la Iglesia Parroquial de S. Justo y Pastor, de Toledo, desde el Año de 1659, hasta el de 1681", fol. 69v. Partida de 29-6-1668). A los tres igualmente se les habria de ver posteriormente en 1682 en la tasación de bienes por muerte de Bartolomé Sombigo, a quien hay que tener por su indiscutible maestro y mentor.

8 A.H.P.T., Pr. 3665, fol. 168, ante Dionisio Ruano. La escritura de fianzas inserta traslados de escrituras otorgadas en Baeza ante el escribano Luis del Pozo, posturas y obligación de obra. En la postura comparecen asociados «Rodrigo carrasco maestro de canteria veçino de la çiud. de toledo parroquia de san laurençio y Juan barrajon maestro carpintero veçino de la dicha çiudad parroquia de san Juan bautista". Sin embargo, fue Juan de Mendoza, estante también en la ciudad, quien mejoró la postura y en quien remató la obra por 36.000 ducados, comprometiéndose a darla acabada en tres años. De regreso a Toledo, Rodrigo Carrasco y Juan Barrajón, otorgan su poder en 16 de octubre a favor de Mendoza para avalarle en la obligación de la citada obra (A.H.P.T., Pr. 3665, fol. 177).

9 A.H.P.T., Pr. 3713 , fol. 364, ante Juan Flores González. Escritura de 3 de diciembre, de "Andres Diaz de los Herreros y Rodrigo Carrasco encargo de Reja". 
Juan de Mendoza y Juan de la Fuente, en los trabajos de cantería, labrado de zócalos y de dos portadas de piedra berroqueña, para las Capuchinas Descalzas de Toledo, que desde febrero de 1668 a 1672 se acometen bajo las órdenes de Bartolomé Sombigo, el arquitecto que trazó y dirigió tan personalísima y cuidada obra, fundación expresa del Cardenal Pascual de Aragón 10. Por entonces, en 1668, parece ser que Rodrigo Carrasco hizo las jambas de la portada de piedra de la parroquia mozárabe de Santa Justa y Rufina de Toledo 11. Obras que aún perduran en los edificios que las engloban.

Por otra parte, el Ayuntamiento de Toledo realizará «los Reynchidos y solado de la Puente de S. Martin», en que intervendrá Rodrigo Carrasco, al rematar en él la obra en 3 de diciembre de 1670, tras las distintas posturas presentadas en Toledo por el propio Rodrigo Carrasco con Juan de Mendoza (en 10 de octubre de 1670); por Francisco de Huerta y Pedro González (vista en ayuntamiento en 20 de noviembre); por Rodrigo $\mathrm{Ca}$ rrasco y Juan de Mendoza en una segunda baja (vista en 2 de noviembre); y por Jerónimo de la Vega (admitida en 22 de noviembre). Las trazas y condiciones para la obra estaban firmadas por Bartolomé Sombigo, a la sazón maestro mayor de las Obras Reales, en Toledo a 12 de octubre de 1670 , valorando todo en 47.137 reales. Adjudicada la obra en el propio Carrasco, éste declaraba en la misma fecha del remate por sí mismo y en nombre de sus compañeros Francisco de Huerta y Pedro González, otorgando escritura de obligación al día siguiente, signada de los tres canteros como principales, y fiados por Luis Maldonado Espinosa y Juan de Herrera, maestros de albañilería de Toledo 12. En razón de prevenir la piedra, portes y otros materiales y pagar jornales de oficiales fue por lo que «Rodrigo Carrasco, vecino desta ciudad y maestro de canteria" daba poder in solidum a sus otros dos socios para, en su ausencia, cobrar el dinero a tal efecto 13 . Igualmente, en ese año de 1671, compa-

10 A.H.P.T., Pr. 342 , tol. 5, ante Manuel Ruiz Machuca. Carta de pago otorgada por Juan de Mendoza y Rodrigo Carrasco (en Toledo, 2-1-1672) correspondiente a la tercera medida o tasación de la cantería hecha entre 5 de febrero de 1668 hasta la fecha, recibiendo 139.004 rls. Ciertamente, la obra se encargó en 3 de enero de 1668, Véase SUAREZ QUEVEDO, D.: Arquitectura Barroca en Toledo. Siglo XVII, Toledo, 1990, pág. 191. Quien supone a partir de 1671 a los tres canteros en la fábrica del claustro, propiamente labrando las columnas de los dos pisos.

11 RAMIREZ DE ARELLANO, R.: Catálogo de artifices que trabajaron en Toledo, y cuyos nombres aparecen en los archivos de sus parroquias, Toledo, 1920, pág. 50.

12 Archivo Municipal de Toledo (A.M.T.), Caja Obras puentes S. Martin (1570-1699). Expte. "Año de 1670 asta 1673. $\operatorname{sep}(\mathrm{ti}) \mathrm{m}^{\circ} \mathrm{q}$ (uader) $\mathrm{n}^{\circ}$. Puentte de S. Mtn”.

13 A.H.P.T., Pr. 323, fol. 169, ante Diego Fernández Ramila. Escritura de «Rodrigo Carrasco Poder a Franco de Guerta y a Pedro Gonzalez", de fecha 19-5-1671. La firma completa del artifice es $R 0^{-}$ drigo Carrasco y Gallego. 
recen ante los comisarios de la obra municipal Rodrigo Carrasco y Francisco de Huerta, ante cuya convincente exposición se ordena quitar las casas de Alcaide y Aduanas que estaban en los apartaderos del medio para dar más amplitud al paso central del puente 14 . Ya en 3 de septiembre de 1671 firmaba Rodrigo Carrasco una cuenta de la obra por un importe de 4.642 rls.; y las reparaciones sumaban 3.883 rls, según ajuste también firmado por él en Toledo a 8 de diciembre de 1671 15. En este mismo año, a 30 de diciembre, el escultor toledano Juan Gómez Lobo junto a Rodrigo Carrasco, que se dice cantero, y el ya mencionado Juan Barrajón se constituyeron en fiadores del cantero Juan de Mendoza, obligado a hacer esta vez la obra de la iglesia parroquial de San José de Cazorla, para construir crucero, cuerpo de iglesia y sacristía 16 , por lo que hay que considerar la frecuente asociación de Rodrigo Carrasco con el citado maestro toledano que se hallaba destinado al servicio del arzobispado de Toledo en sus posesiones del Adelantamiento de Cazorla.

Estando aún en Toledo, Rodrigo Carrasco se comprometía después de febrero de 1672 a ejecutar la obra de la escalera principal del claustro del hoy desaparecido convento del Carmen Calzado de esa ciudad, obligación de la que se hubo de excusar por su traslado a Madrid, y que asumió en 15 septiembre de ese mismo año su compañero Pedro González "mro. de canteria y becino desta ciud. de Toledo y dixo que por quanto Rodrigo Carrasco ansimesmo becino de ella y mro. de canteria se encargo de açer y fabricar en el conbento de nra. $s^{a}$ del carmen de antigua obserbancia desta ciud. una escalera de piedra berroqueña y un antepecho con su predestal y solar dos mesas que es la del oratorio y poner del antepecho y predestal lo qual el dho Rodrigo Carrasco no puede acabar sin enbargo de tener Reçebida toda la cantidad en que se conçerto asi de manos como de materiales por estar en la billa de Madrid en algunas ocupaciones ..."17. Aún entonces el maestro de cantería, en abril de ese

14 A.M.T., Libro de Actas Capitulares 1671, fol. 103. Expediente "Parecer tocante a la obra de la puente de san martin" (1671).

15 A.M.T. Caja Obras puentes S. Martin (1570-1699). Expediente «Año de 1670 asta 1673. sep(ti)m ${ }^{0}$ q(uader)n. Puentte de S. Mtn». Tras la tasación de Bartolomé Sombigo en 29 diciembre, y una posterior declaración de 11 de mayo de 1672, por la que ve es necesario se retunda y repare el solado ya hecho, se procedió a la prisión de Francisco de Huerta en 12 de marzo de 1673 por no haber cumplido el contrato de obra; y Bartolomé Sombigo certificará en 18 de marzo el reparo requerido. A ello se sucede la petición de los obligados para el libramiento de pagos; $y$, en efecto, en 10 de abril de 1673 se le pagan a Francisco de Huerta 384 reales que se le debian.

16 A.H.P.T., Pr. 3728, fol. 521, ante Gabriel de Romani.

17 A.H.P.T., Pr. 323 , fol. 714, ante Diego Fernández Ramila. En razón del apremio, se obliga el otorgante a dar acabado lo que faltaba en quince dias. Las aludidas ocupaciones madrileñas fueron probablemente la obra que por entonces se iniciaba en el puente de Toledo, pues en 13 mayo de 
año, está otorgando poder a otro cantero vecino de Toledo, Alonso Moreno de la Parra, para que en su nombre reciba y cobre de don Bernardo Patiño, Contador mayor del Gran Prior de la Orden de San Juan, Su Alteza Real don Juan de Austria, la cantidad de 2.500 reales del resto de los 10.000 ajustados en «la obra de los chapeados de marmol para el salon de los aljibes y gradas para el despacho de Su Alteça y el dormitorio y saleta o retrete de las casas que Su Alteza tiene en la billa de Consuegra", capital del Priorato de Castilla 18.

Hacia 1673 y 1674 debía seguir frecuentando la villa de Madrid mientras alterna con la obra que se llevaba a cabo en el convento de Santa Juana de la Cruz, en Cubas de la Sagra (localidad madrileña a unos 40 $\mathrm{km}$ al norte de Toledo). Es así que en 10 de junio de 1675, en Toledo, Ignacio de Arteaga, un oficial de cantería vecino de esta ciudad, otorgaba su poder y cesión de derechos a Juan Moreno Ramírez, también vecino, para cobrar de Rodrigo Carrasco, "maestro de cantería y vecino de Toledo", 529 reales de vellón que le debía de ajuste de cuentas del tiempo que trabajó con él en la obra del referido convento madrileño en el año de 167419.

En Toledo los trabajos en el puente de San Martín se reanudan en 1675 con el alzado de antepechos y remates de piedra y el allanamiento de los dos descansos abiertos. Para conseguir la obra se admiten dos únicas posturas, la de Francisco de Huerta, presentada en 15 de diciembre de 1674, y la de Rodrigo Carrasco, en 29 de diciembre; rematando en este último la obra ya en 9 de enero de 1675. Del mismo modo que en 1670 , tras la adjudicación Rodrigo Carrasco por sí y en nombre de Francisco de Huerta y Alonso Moreno, maestros de cantería, se obligan como socios en 11 de enero a cumplir las condiciones de Bartolomé Sombigo, que evaluaba los costes en 55.000 reales, dadas en Toledo a 22 abril de 1673 y revisadas en 29 de noviembre de 167420 . Pero los trabajos que-

1672, Tomás Román, maestro de obras de la villa, por comisión de Juan Ramírez de Arellano, superintendente de la obra y fábrica del puente de Toledo, daba poder a favor de Rodrigo Carrasco y Nicasio Román, para conseguir las carretas que transporten la piedra para la obra; y, por otra parte, en 2 de septiembre, se concertaba la obra del claustro del convento de Antón Martín, entre su superior Fray Francisco de San Antonio y los maestros de obras Rodrigo Carrasco y Nicasio Román, Véase BARATECH ZALAMA, Mํㅡㄹ Teresa: Catálogo de documentos. Siglos XVI y XVII, vol. I, 1998, págs. 129 y $130, \mathrm{n}^{2} 1057$ y 1062.

18 A.H.P.T., Pr. 3566, fol. 717, ante Juan Gutiérrez de Celis. El poder, con fecha de 20 de abril de 1672 . 19 A.H.P.T. Pr. 3845, fol. 191, ante Manuel Ruiz Machuca. Sabemos que en 7 de septiembre de 1666 Bartolomé Sombigo y Salcedo firmaba con el convento de franciscanas de Cubas de la Sagra el contrato para hacer una urna y tabernáculo donde se habría de poner el cuerpo de la Santa Juana de la Cruz, documentos en AGULLO Y COBO, Mercedes: “Pedro, José, Francisco y Jusepe de la Torre, arquitectos de retablos", AIEM, tomo XXXVII, 1997, pág. 37. 
darían suspendidos, tal vez con la ausencia definitiva de Carrasco de la Ciudad Imperial. Años después, respecto a la obra en relieve del escudo de armas de Toledo que se ejecutaba para ornato de la puerta interior del mismo puente, Rodrigo Carrasco sería designado tasador junto al maestro escultor de Madrid Manuel Gutiérrez (quien se hallaba ocasionalmente trabajando en Toledo para los agustinos calzados), según nombramiento municipal acordado en 12 de noviembre de 1689, siempre y cuando pudiesen asistir a esta comparecencia como peritos 21 . Una obra más en Toledo realizó, según Llaguno, Rodrigo Carrasco, siendo ya vecino de Madrid, junto a Diego González, maestro de albañilería vecino de Toledo, como fue acabar los cuatro lienzos o tapias que cerraban el jardín del convento de Mínimos de San Bartolomé de la Vega, ya en el año de 167522 .

Afincado definitivamente en Madrid, donde la actividad constructiva es más intensa, en 1676 está en la obra del puente de Toledo 23 y en 1677 estaba trabajando en el convento de Trinitarias Descalzas y en la Cárcel Real 24. Prueba de esta permanente estancia madrileña es que, en abril de 1680 por escritura otorgada en Toledo, Isabel Moreno, madre y curadora de su hijo Andrés de Ribera, de 18 años, da poder a Rodrigo Carrasco «mro. de cantteria residente en la villa de Madrid» para que en su

20 A.M.T. Caja Obras puentes S. Martin (1570-1699). Expediente "Año de 1674 y 1675 asta 1683. octavo q(uader) $n^{\circ}$. Puente de S. Martin". Terminada la obra, la tasación se hace en 23 de abril de 1676 por Bartolomé Sombigo, con un gasto superior al calculado de 61.735 rls.

21 A.M.T. Caja Obras puentes S. Martin (1570-1699), Expediente "Año de 1688 asta 1692. onceno q(uader)no. Puente de S. Martin. Condiciones $\mathrm{pr}^{\mathrm{a}}$ las Aguilas imperiales que se an de acer para el Puente de S. Martin desta ciud.". Los comisarios de esta obra, en vista de que la obra de las armas y águilas estaban acabadas y antes de fijarlas en el muro upor el yncoveniente que puestas tiene para la tasacion en cuya virtud nombran por tasador de dha obra armas y aguilas a Rodrigo Carrasco maestro de canteria y a el $\mathrm{m}$ (aestr) ${ }^{9}$ que esta en esta ciud. a cuyo cargo esta la efigie de $\mathrm{Sn}$. agustin y no pudiendo concurrir estos se dexa a eleccion del Sr. Don Alonso el que venga de $M($ adri)d. el que le pareciere fuere de mayor satisfaz(io)n y senalaren.". Palomino en sus Vidas da noticia de este escultor madrileño y una efigie de S. Agustín de piedra para la portada de la iglesia conventual, hoy perdida.

22 LLAGUNO Y AMIROLA, E: Noticias de los Arquitectos y de la Arquitectura desde su Restauracion, t. III, pág. 182.

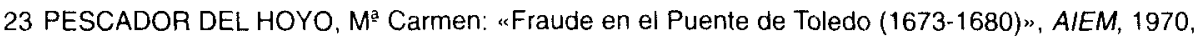
VI, págs. 85-113. La obra se habia empezado en 1672, por Juan de León, Marcos López, Pedro Lázaro Goiti y Luis Román, con las trazas de José de Sopeña, Bartolomé Sombigo y Juan de Lobera. En 1676 la obra seguia y los arquitectos Juan Barboso, Juan de Pineda y Rodrigo Carrasco presentaban memoria y dibujo sobre algunos detalles para las bajadas laterales.

24 TOVAR MARTIN, $V .:$ “El arquitecto Marcos López y el convento de las Trinitarias descalzas de Madrid", AlEM, 1974, X, págs. 133-153. La primera piedra se colocó en 16-9-1673, con planos de Marcos López, maestro de obras y alarife. Por otra parte, Rodrigo Carrasco, arquitecto, y Juan Gonzalez, maestro ensamblador, son testigos en la escritura de poder que otorga en Madrid José López en 5 de mayo de 1677 a su padre Marcos López para testar. En 1677 este José López de. 
nombre ponga a servir y aprender oficio de platería al muchacho 25; como significativo es que en 1682, a la muerte en Toledo de Don Bartolomé Sombigo y Salcedo, Rodrigo Carrasco fuera nombrado por los testamentarios para medir las casas que en el barrio de Lavapiés poseía el maestro mayor toledano 26.

Sin duda, Rodrigo Carrasco adquirió un notable prestigio cerca de la Corte lo que le permitió ser distinguido en 1686 con una Real Cédula nombrándole en el cargo de sobrestante para la asistencia y gobierno en todas las obras de la embocadura y caz del río Jarama, por su calidad de «maestro de obras, architecto y de hacer presas", si bien el rey le eximía de la obligación de asistir permanentemente al delegar funciones en el maestro de obras Juan Antonio Ablay, nombrado su teniente en el cargo 27.

Así, integrado plenamente en el medio madrileño y habiéndose trasladado con su familia, Rodrigo Carrasco Gallego casó a sus dos hijas. En 1680 a María Carrasco con el maestro de cantería Juan Antonio de la Peña y Arroyo, siendo padres de María de la Peña y de Josefa de la Peña 28. Las dos nietas se constituirian en herederas universales de su abuela materna, que testó en 1709, y con ello, depositaria la primera de ellas de la biblioteca del arquitecto de origen toledano, legado que, al estar casada con Alberto de Churriguera, recayó en este arquitecto madrileño 29. En 1689 contraía nupcias Escolástica Carrasco con Manuel López Rincón 30.

claraba en su propio testamento estar ejecutando en la Cárcel Real de la villa unos calabozos y un lienzo de fachada en compañía de Rodrigo Carrasco. Además, el maestro de cantería Cristóbal Durango, vecino de Toledo, en su testamento otorgado en esta ciudad en 31 de octubre de 1677, declara en una de sus cláusulas: "todas las alajas y trastos que estan en esta casa que de presente vivo son de Rodrigo Carrasco maestro de canteria que oi reside en M(adri)d. que se le den y entregue a la persona que ordenare ..." (A.H.P.T., Pr. 3706, s/f., ante el escribano Gabriel de Morales).

25 A.H.P.T., Pr. 3464 , fol. 219 , ante Martín de Villaseñor.

26 RODRIGUEZ MARTIN, J. M: El arquitecto toledano Bartolomé Sombigo y Salcedo (1620-1682), Toledo, 1989, pág. 32. El inventario y tasación de bienes se hace en agosto de 1682, con Pedro González, aparejador de la Santa Iglesia, tasando las herramientas del oficio de arquitectura; Rodrigo Carrasco y Gallego, maestro de obras de cantería, remite con fecha de 16 de ese mes la tasación de las casas en Madrid; y las de Toledo de nuevo por González y Francisco de Huerta, alarife municipal (A.H.P.T., Pr. 191, fol. 1013).

27 Archivo de Palacio Real, Reales Cédulas, T. XVI, fol. 615v. Dada en Madrid a 26 de marzo de 1686.

28 Archivo Histórico de Protocolos de Madrid (A.H.P.M.), Pr. 10746, fol. 692, ante Eugenio García Coronel. Escritura de capitulaciones matrimoniales otorgada entre Rodrigo Carrasco Gallego y su mujer y $D^{\Xi}$ María Carrasco, su hija, y Juan de la Peña, en Madrid a 5 de mayo de 1680 . Como testigo firma Joseph Donoso.

29 VERDU RUIZ, M.: "Nuevos datos sobre Alberto de Churriguera y su obra en Madrid: el retablo de la capilla mayor del convento de San Basilio Magno. Herencia de la biblioteca del arquitecto Rodrigo Carrasco", AlEM, 1996, XXXVI, págs. 153-162.

30 A.H.P.M., Pr. 10751, fol. 36, ante Eugenio Garcia Coronel. Escritura de capitulaciones matrimoniales, en Madrid a 30 de enero de 1689. Como testigo firma Joseph Donoso. 
Llaguno afirma que «Rodrigo Carrasco residia con crédito en Madrid, donde falleció el día 5 de enero de 1690. Fue sepultado en la iglesia de los Padres Mínimos de la Victoria en la sepultura que está debajo del púlpito, segun consta de los libros de difuntos seculares de aquel convento» 31.

Contamos con el testamento de este maestro marmolista y cantero, otorgado en Madrid a 29 de diciembre de 1689, donde se revelan algunos datos biográficos 32 . Como ya dijimos, él era vecino de Madrid y se confesaba natural de Consuegra, villa toledana del Priorato de San Juan, siendo sus padres, ya difuntos, Martín Carrasco, natural de Ayo, encartación de Vizcaya, y María Gallego, natural del mismo Consuegra. Nombraba por herederas universales a sus dos hijas y por sus albaceas a su mujer, al padre Fray Tomás Reluz, prior del convento de dominicos de Santo Tomás de Madrid, al pintor José Donoso y al arquitecto José de Arroyo; firmando como testigos José de Churriguera, José de Lara y Simón Meléndez. $Y$ mayor interés documental tiene la escritura de partición de bienes otorgada entre su viuda Isabel Bautista Lázaro y las dos hijas, en Madrid a 3 de marzo de 1690 33. A tenor de estos dos documentos fundamentales, podemos ampliar el catálogo de su obra madrileña. Confirmamos así su intervención en la obra del convento de benitos de Montserrat, y la dirección de la obra del caz del Jarama, pero noticias inéditas son que junto a Antonio de Arce, maestro de obras de Madrid, hizo la casa del Abad y Monjes del convento parroquial de San Martín, contigua a la capilla mayor de la iglesia; con Francisco Mingo, maestro de obras, tenía empezada otra casa frente a la fuente de la Puerta del Sol, de orden del reverendo padre Fray Alonso de Castro de los Mínimos de la Victoria; habia intervenido en la obra del colegio de los dominicos de Atocha y a su cargo había estado la ejecución del retablo mayor de mármoles de la parroquia de Santa Maria de la Almudena. Además, Rodrigo Carrasco, maestro cantero, había contratado en 1678 con Francisco de Aizpuro,

31 LLAGUNO Y AMIROLA: Op. cit., t. IV, pág. 84.

32 A.H.P.M., Pr. 10751, fol. 472, ante Eugenio García Coronel.

33 BARATECH ZALAMA: Op.cit, pág. 165. El documento original, en A.H.P.M., Pr. 10751, fols. 584 $640 \mathrm{v}$, "Ajuste y partc ${ }^{\mathrm{n}}$. de los vienes de Rodrigo Carrasco otorgada entre su muxer y las hijas del susodho". Por este se obtienen algunos datos interesantes. Muere efectivamente en 5 de enero de 1690 , y vivia en casas con puerta principal a la calle de los Abades, frente a la puerta de San Cayetano (y entrada secundaria por la calle de Dos Hermanas), casas que habia adquirido por compra en 1685 a Alonso Guerrero, Familiar del Santo Oficio de la Inquisición y Alguacil de Casa y Corte. De entre los efectos de la profesión se inventarian diversas carteras con papeles de trazas, plantas y dibujos de arquitectura, distintos compases (que se dicen vendidos a José de Churriguera) y una interesantísima biblioteca de varios autores y tratadistas de arquitectura, que pasó como herencia a la mujer, además de algunas pinturas. 
maestro de obras y alarife de la villa, según trazas de éste, la obra de cantería en las casas principales y accesorias del Marqués de Astorga y Velada, en la calle del Soldado, en el Barquillo 34.

La biografía de Rodrigo Carrasco, maestro de cantería de la segunda mitad del siglo XVII, aparece si cabe más completa al conocerse su periodo toledano aquí reseñado, que antecede al ya bien conocido periodo madrileño, lo que supone centrar en Toledo una actividad desarrollada entre 1660 y 1672, con algunas idas y venidas hasta su definitivo establecimiento hacia 1676 en la Villa y Corte. Suponemos que su entrada en Madrid y en los círculos cortesanos vino de la mano y protección del pintor y arquitecto José Jiménez Donoso (1628-1690), paisano de Rodrigo Carrasco por haber nacido también en Consuegra y mayor en edad, y a quien tal vez recomendó cuando aquél pintaba el techo del vestuario de la catedral de Toledo entre 1672-1673 35. Aún así, queda todavía incierta su etapa de aprendizaje, sin conocer la relación con su hermano mayor también maestro de cantería, Agustín Carrasco Isasi 36, si bien hemos de considerar la proximidad al taller toledano de Bartolomé Sombigo y Salcedo y la grandiosa obra del Ochavo catedralicio, en espera de otras precisiones que habrán de desvelar los documentos toledanos enriqueciendo el perfil artístico de este maestro consagrado como arquitecto del Madrid barroco, práctico en cantería y trabajo del mármol, y cuya

34 A.H.P.M., Pr. 10751, fol. 393. Carta de pago otorgada por Rodrigo Carrasco a favor de Matias Román y los herederos de Francisco de Aizpuro, en 24 de octubre de 1689, con lo que se le pagaban unas cantidades de la obra que en 1684 había demandado judicialmente, habiendo sido tasada por Felipe Sánchez y Manuel del Oimo, maestros de obras.

35 CEAN BERMUDEZ, A.: Diccionario de los más ilustres profesores de las Bellas Artes en España, Madrid, 1965 (Ed. facsímil 1800), t. VI, págs. 8-13. La fecha de muerte de Jiménez Donoso hay que retrasarla efectivamente a $\$ 690$, pues ya se ha visto que fue nombrado su albacea por Rodrigo Carrasco en 29 de diciembre de 1689, señalándo Ceán Bermúdez la fecha de entierro en 14 de septiembre de aquel año.

36 Agustin Carrasco, ya difunto en 1658, hubo de ser mayor e hijo de un matrimonio anterior del padre, a juzgar por el segundo apellido /sasi con que figura en los documentos. Afincado en Toledo, es fiado en 8 de mayo de 1655 por Gaspar de Olaza, también cantero vecino de Toledo, en el alquiler de una casa del Cabildo catedralicio en la parroquia de San Bartolomé por tiempo de un año (A.H.P.Y., Pr. 3156, fol. 983, Rodrigo A. de Hoz); en 23 de ese mes y año se obligaban Gaspar de Olaza, Agustín Carrasco y Francisco Solano, canteros de Toledo, a labrar la portada de la iglesia conventual de Benitas Recoletas de esa ciudad (A.H.P.T., Pr. 3528, fol. 505, Nicolás López de la Cruz), teniéndola acabada en 13 de febrero de 1656 (A.H.P.T., Pr. 3529, fol. 84, Nicolás López de la Cruz); en marzo de ese año Agustín Carrasco y Gaspar de Olaza se obligan, con condiciones y traza de José de Ortega, copiando el modelo del púlpito de los dominicos de S. Pedro Mártir, a labrar en mármoles de San Pablo de los Montes el púlpito de la iglesia de la Trinidad Calzada (A.H.P.T., Pr. 3529, fol. 132, Nicolás López de la Cruz); por último, en 14 de agosto de 1657 Agustín Carrasco otorga poder en Toledo a su socio Gaspar de Olaza y, a los que dice «mis compañeros", Antonio Sormano, Juan de Lobera y Miguel de Tapia para en su nombre obligarse a la obra de la capilla de San Isidro en la parroquia de San Andrés de Madrid (A.H.P.T., Pr. 3524, fol. 395, Nicolás López de la Cruz) 
vida apenas alcanzó los cincuenta años.

\section{APENDICE DOCUMENTAL.}

Testamento otorgado por Rodrigo Carrasco y Gallego.

Madrid, 29 de diciembre de 1689.

Archivo Histórico de Protocolos de Madrid, no 10751, fols. 472-476.

“ En el nombre de Dios todo poderoso Amen: sea notorio a los q-. la presente escriptura de testamento y ultima disposizion y voluntad, vieren como yo Rodrigo Carrasco y Gallego, vez ${ }^{\circ}$ de esta villa de Madrid, y natural de la de Consuegra en los prioratos de San Juan hijo lexitimo de lexitimo matrimonio de Martin Carrasco natural q- fue de la villa de Aio encartazion de Vizcaya, y Maria Gallego natural q- fue de dha villa de Consuegra, difuntos. Allandome enfermo del cuerpo y en la cama de la enfermedad corporal que Dios Nro. Sr. a sido servido de darme, si vien y su ynfinita misericordia en mi juizio y entendimt ${ }^{\circ}$. natural segun Dios Nro. Señor a sido servido darme; creyendo como firme y verdaderamt $^{\mathrm{e}}$. creo en el sacrosanto misterio de la Santissima Trinidad Padre Hijo y Espiritu Santo tres personas distintas y un solo Dios verdadero, y en todo lo demas que cree, confiesa y enseña la Santa Madre Yglessia Catholica Romana devajo de cuya fee y crehenzia e vivido y protesto vivir y morir; ymbocando como ymboco $p$ - mi avogada a la siempre virgen maria conzevida en grazia desde el primer ynstanie de su ser natural $p^{a}$ que interzeda con su prezioso hijo encamine mi alma y carrera de salbazion, y temiendo me dé la muerte que es cossa natural a toda criatura, aunque dudosa su hora; y deseando no me halle desprebenido hago y hordeno este mi testamento en la manera sigt ${ }^{e}$ :

- Lo primero encomiendo mi alma a Dios Nro. Sr. q- la crio y redimio con su preziosa sangre, y el cuerpo a la tierra de donde fue formado=El qual mando sea enterrado en la $\mathrm{pt}^{\mathrm{e}}$. que mis albazeas elijieren, a cuya disposizion dejo la forma del acompañamiento.

- Mando se me diga missa de cuerpo presente el dia de mi entierro, siendo hora y sino el siguiente, y se pague la limosna q- es costumbre.

- Mando se me digan quatrozientas misas en esta manera: las ziento en el convo de $\mathrm{Nra}^{\mathrm{S}} \mathrm{Sr}^{\mathrm{a}}$. de la Vitoria de esta corte, otras ziento en el convt $^{\circ}$ de San Cayetano desta $\mathrm{C}^{\mathrm{e}}{ }^{\mathrm{e}}$., zinquenta en el convt ${ }^{\circ}$. de Santo Thomas de predicadores tambien desta $\mathrm{Ct}^{e}$., zinquenta en el Monasterio de monjes benitos desta $\mathrm{Ct}^{\mathrm{e}}$. de $\mathrm{Nra}^{\mathrm{S}} \mathrm{Sr}^{\mathrm{a}}$ de Monserrate. $\mathrm{Y}$ las 
ziento restantes $q$ - reserbo $p^{\text {a }}$ la quarta parroquial, y se paguen a tres reales de limosna cada una.

- Es mi voluntad se den dos rea(le)s. de limosna por una vez a las mandas forzosas $p^{\text {a }} q$ - se rrepartan entre todas ellas, con lo qual las aparto del der $\mathrm{q}$ - podian tener a mis bienes.

- Declaro estoy deviendo a Pedro Diaz mtro. de canteria, vez $z^{\circ}$ desta villa de Madrid, mil y quinientos Reales de vellon, mando se paguen de lo mas prompto y mejor de mi hazienda.

- Declaro se estan deviendo en la Sierra algunas restillas como son a Garpar Terliquez lo que pareziere $p$ - mis rezibos de piedra q- me a entregado trezientos y diez reas. y lo que pareziere mas constara $p$ - mis rezivos de la piedra y en la misma sierra y lugar d(e) Alpedrete se deben al Capon y otro compañero suyo tres portes de piedra q- con declarazion jurada suya se les pague lo que dijeren= en Bezerril sestara deviendo a Juan Gonzalez el viejo y el mozo algunas restillas, q- seste a lo q-ellos declararen y se les pague, que no pueden pasar de quarenta o zinquenta reas. = en el lugar de Bobado y Mataelpino sestaran deviendo a los hijos del Cano y a Carrasco otras restillas como la de arriba poco mas o menos.

- Declaro mestan deviendo de quentass ajustadas de la obra del dho monasterio de Monserrate, dos mil reales de vellon.

- Mas declaro que mestan deviendo todo el produto de la mitad que despues de haverse medido la obra q- emos echo Antonio de Arze Mro. de obras y yo en la cassa contigua a san lldefonso anejo de San Martin desta corte, de orden de su Abad y combento.

- Mas se mesta deviendo de la obra de la cassa q- esta empezada en la puerta del Sol enfrente de la fuente, q- tengo echa de orden del padre fray Alonso de Castro Relijioso de la orden de los minimos de Nra. Sra de la Vitoria de esta corte, la mitad de lo que quedare acabada la obra.

- Mas declaro mesta deviendo Pedro Melendez alguazil de la cassa y corte de Su Magd. duzientos ducados de ve ${ }^{\circ}$. como consta de los papeles que paran en mi poder.

- Ytem declaro q- la obra q- tengo empezada pa el rretablo de Santa Maria se tase lo q-ay echo y piedra para ella, segun el thenor de la escriptura y se bea quien deve a quien para que pague.

- Ytem declaro que estoy cassado segun orden de Nra. Santa Madre Yglesia con Doña Ysabel Baupt ${ }^{a}$ Lazaro; y el caudal que llebo a mi po- 
der, y q- heredo $\mathrm{p}$ - muerte de sus padres, todo ymporta setezientos ducados de vellon, de cuya cant ${ }^{d}$. no tiene resguardo mio alguno, mando se la de satisfazion de ello, y tengo la prelazion de vienes dotales y hereditarios; y respecto de no haver prezedido carta de dote, capitulazion matrimonial ni otro ynstrumt ${ }^{\circ}$. en que yo pudiera haver mostrado el cariño y volunt ${ }^{d}$. que la tenia señalandola alguna porzion por via de arras q- fuese de mas augmento de su dote; aora en la via y forma que mas aya lugar, la mejoro en atenzion de lo rreferido, en el rremanente que quedare del quinto de mi hazienda; y la ruego me encomiende a Dios.

- Yten declaro que de los dos años que di de comer a Juan de la Peña mi yerno y a $D^{a}$ Maria Carrasco y Gallego mi hija y su muxer; fue en atenzion de asistirme dho my yerno como me asistio tres años a mis obras, y los seis años de cassa q- le di fue en considerazion de no haverle pagado quinientos ducados de los mil y quinientos q- le ofrezi $\mathrm{qd}^{\circ}$. casso con la dha my hija; los quales dhos quinientos ducados todavia se estan por entregar; y aunq-comio otros años conmygo pagaba su dinero; y lo q- a comido se cora (sic) despues de viuda, y por que a Manuel Lopez Rincon, qd $^{\mathbf{o}}$. casso con $\mathrm{D}^{\mathrm{a}}$ Escolastica Carrasco y Gallego mi hija, le ofrezi dar un año de comer; en esto ay de difrenzia de un año; les encargo entren en yguales partes sin q- tengan difrenzias q- asi lo fio como buenos hijos.

- Mando se den a fray Facundo Gallego Relijioso de los minimos de esta $\mathrm{Ct}^{\mathrm{e}}$. ziento y zinquenta reales de ve $\mathrm{e}^{\mathrm{o}} \mathrm{n}$. para $\mathrm{q}$ - los destribuya en lo q- le tengo comunycado.

- Ytem declaro q- tengo en mi poder ziento y zinquenta reales de limosnas y condenaziones de la obra del caz para un dosel para el Horatorio de la hermita q- esta en dho caz $\mathrm{md}^{\circ}$. se den a quien los aya de haver.

- Mando a los muchachos Phelipe Castaño, por q- yasta para salir de cassa se le den trezientos y zinquenta reales $p^{\mathrm{a}}$ un bestido y se le den dos camisas de lienzo hordinario; y la erramienta que tiene; a Juan Fernandez se le de un besíido con capa del genero de paño q- trae aora puesta y seis herramientas; y a Franc ${ }^{\circ} q$ - se le haga otro bestido de paño como el que aora trae.

- Yten declaro se le ajuste al que trajo el carbon lo que ymporta sobre seis doblones que tiene rezebidos $q$ - le faltaron tres reas. de vellon, $y$ se le pague lo que se le rrestare. 
- Declaro estoy deviendo a Vizente el ropero, sobre veinte Reales q- tienen rezevidos el rresto de lo que ymportare un calzon y ropilla q- hizo a frayquillo.

- Mando se bean y reconozcan los papeles de la testamentaria del dho Juan de la Peña my yerno, y se ajuste la quenta del dinero que para su cumplimiento e puesto, y se le hagan buenos a mi hija $\mathrm{D}^{\mathrm{a}}$ Maria lo qesta ubiere desembolsado, aunq- esten en mi cabeza los rezivos, y lo que yo alcanzare se rreintregue a my hazienda.

- Mas declaro y mando se le de satisfazion al sachristan de Bezerril y compañeros de otras restillas de piedras, lo que ellos dijeren.

- Yten declaro que si empoder del dho Padre fray Facundo Gallego se hallare una memoria escripta y firmada de su mano q- empezara Christo Domine Ymbocato, es mi voluntad y mando se cumpla obserbe y execute todo lo que en ella se contubiere como si aqui fuera exspresado por que asi es mi voluntad la qual se entregara luego que yo aya fallezido al prest ${ }^{e}$. escrivo para q-. la ponga a continuazion deste mi testamento en los traslados q- de el diere y aiude con el devajo de disignio.

- Dejo por mis testamentarios a la dha Doña Ysabel Baupt ${ }^{\mathrm{a}}$. Lazaro mi muxer, y al muy Reberendo $P^{e}$. fray Thomas Reluz del orden de predi-

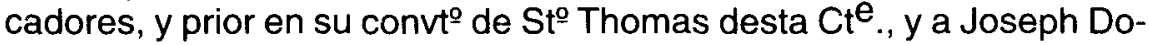
noso y Joseph de Arroyo $v^{\circ} z^{\circ}$ s. desta villa y a cada uno ynsolidum doy poder en forma $p^{\text {a }} q$ - despues de mi fallezimt ${ }^{\circ}$ entren en mis bienes y los vendan en pubc almoneda o fuera de ella; y de su produto cumplan y paguen lo que dejo dispuesto en este mi testamt ${ }^{\circ}$ y les dare este poder todo el tiempo q- sea nezessario sin embargo de q- sea pasado el año del albazeazgo.

- $Y$ el residuo que quedare de todos mis bienes y hazienda $q$ - en qualquier via me toque y pertenezca; dejo nombro e ynstituyo $p-$ mis unicas y unibersales herederas en todo ello a las dhas Doña Maria y $D^{a}$ Escolastica Carrasco y Gallego mis hijas lexmª ${ }^{\mathrm{a}}$. havidas y procreadas constante mi matrimo con la dha $D^{a}$ Ysabel mi muxer y su madre $y$ las pido y ruego me encomienden a Dios y rreboco y anulo y doy por ningunos y de ningun balor ni efecto otros qualesquier testamentos, cobdizilios poderes para testar y otra qualquier disposizion q- por escripto u de palabra yo aya echo, antes de aora q- quiero no valgan, ni hagan fee en juizio ni fuera de el salbo este; y otra memoria q- es mi voluntad un y otro valga de ese y sirba $p$ - mi testamento y ultima dis- 
posizion q- mas aya lugar en derecho, y assi lo otorgo ante el pret $\mathrm{t}^{\mathrm{e}}$. ssno. y testigos q- lo fueron prestes. Joseph de Churriguera, Joseph de Lara, Simon Melendez, Phelipe Garz a Castaño y Juan Fdz. Alonso redtes. en esta $\mathrm{Ct}^{\mathrm{e}}$. y Villa de Madrid, q- es fho en ella entre doze $y$ una (entre renglones: de la noche) del dia veinte y nuebe de Diziembre de mil seiss ${ }^{\circ}$ s. y ochenta y nuebe y el otorgte. que yo el ssno. doy fee conozco no puede firmar $p$ - la grabedad de su enfermedad y a su ruego lo firmo uno de dhos testigos y assimiss ${ }^{\circ}$ lo firmaron otros dos de ellos doy fee.

Testigo por el otorgante Joseph de Churriguera, testigo Simon Melendez, testigo Joseph de Lara, ante mi Eugenio García Coronel» 
